\title{
The Impact of Macro- and Micro-Economic Uncertainty on Family Formation in The Netherlands
}

\author{
Marloes de Lange • Maarten H. J. Wolbers • \\ Maurice Gesthuizen • Wout C. Ultee
}

Received: 10 February 2013/Accepted: 25 September 2013/Published online: 28 January 2014

(C) Springer Science+Business Media Dordrecht 2014

\begin{abstract}
In this paper, we study the impact of macro- and micro-economic uncertainty on family formation between 1970 and 2000 in The Netherlands. Using data of the Family Survey Dutch Population, we analysed the monthly hazard rates of experiencing the transition into first union, first marriage and parenthood after the start of the relationship of 365 male and 364 female partners by applying piecewiseconstant exponential models. The results show that macro-economic uncertainties, i.e. high unemployment rates, lead to postponement of the first union and marriage, but not of the first child. In addition, we found that this relationship is not interpreted by individual-level employment insecurity, i.e. temporary employment or unemployment, which does not seem to prevent people from making long-term family commitments. Although hypothesized, we did not find that the negative effects of macro- and micro-level insecurities on family formation reinforce each other or that they vary between individuals with different educational qualifications.
\end{abstract}

Keywords Family formation - Macro-economic uncertainty ·

Employment insecurity · Couples · Retrospective data · The Netherlands

\section{Introduction}

Since the mid-1960s, marriage and fertility rates declined strongly due to the rise in mean age at first marriage and parenthood, while there was an increase in divorce and separation, cohabitation, and the number of extramarital births (Lesthaeghe and van de Kaa 1986). The invention of efficient methods of contraception played an important role in these demographic changes. During the 1970s and 1980s, macro-

M. de Lange $(\bowtie) \cdot$ M. H. J. Wolbers · M. Gesthuizen · W. C. Ultee

Department of Sociology, Radboud University Nijmegen, P.O. Box 9104, 6500 HE Nijmegen,

The Netherlands

e-mail: m.delange@maw.ru.nl 
demographic features of this so called 'Second Demographic Transition' (Deboosere et al. 1997; van de Kaa 2002; Liefbroer and Puy 2005) rapidly spread over other industrialised countries. Two types of explanations for this transition were initially discussed in sociological literature: a cultural and a structural one. Cultural explanations comprise changes in value systems from being family oriented to accentuating self-development and self-fulfilment (Deboosere et al. 1997; van de Kaa 2002), due to secularisation and post-materialism or modernization (Inglehart 1977, 1997). Structural explanations involve developments as globalisation (Mills and Blossfeld 2005), educational expansion (Bell 1976; Klijzing 2005) and increasing female labour market participation, which induced economic independency among women (Becker 1981) and explain decreasing marriage and fertility rates (Deboosere et al. 1997; Hannum and Buchmann 2003).

In this paper, we discuss the role of macro- and micro-level economic uncertainties in explaining family formation in The Netherlands since the 1970s. It is assumed that poor economic conditions signal poor labour market prospects and economic insecurities (see, for instance, Kreyenfeld et al. 2012; Sobotka et al. 2011). Until the late 1960s, the economic situation in European countries was prosperous, reflected by extremely low unemployment levels-our measure of economic uncertainty (Blanchard 2006). Due to the economic crises in the 1970s and 1980s, unemployment rates increased sharply. Young couples might perceive family formation as too risky under such circumstances (McDonald 2002; Neels 2010; Schmitt 2008).

Our first research question is as follows: To what extent do macro-economic uncertainties lower the family formation rate for individuals? We expect this macro-level effect to be channelled through individual employment insecurity: Economic adversity increases the likelihood to be un- or temporarily employed, which in turn leads to postponement of family formation. This leads to the following research question: To what extent can the negative relationship between macroeconomic uncertainties and the family formation rate be explained by individual employment insecurity? Additionally, macro- and micro-level insecurities might reinforce each other, as individuals with an insecure employment position could feel discouraged to make long-term family commitments if economic prospects are poor, i.e.: To what degree is the negative effect of individual employment insecurity on the family formation rate strengthened by macro-economic uncertainties? Finally, effects of macro- and micro-level insecurities likely differentiate between people with varying educational qualifications, due to differences in opportunity costs associated with family formation (Gebel and Giesecke 2009; Liefbroer and Corijn 1999; Sobotka et al. 2011). Our final research question reads: To what extent do the negative effects of macro-economic uncertainties and individual employment insecurity on the family formation rate vary between individuals with different educational qualifications?

We focus on The Netherlands, analysing retrospective data of the Family Survey Dutch Population collected in 2000 (de Graaf et al. 2000). We analyse individuals and their partners in the period 1970-2000, in which changes in demographic changes related to family formation actually occurred. In Sect. 2, we provide a brief 
overview of these changes, as well as cultural, structural and macro-economic developments in this period.

We improve upon previous studies in several ways. First, as Sobotka et al. (2009, 2011) have pointed out, the relationship between economic recessions and decreasing family formation rates is frequently assumed in media and politics in developed countries, but systematic research on the existence of and explanation for this relationship is still lacking. In most studies, only the macro-level relationship between economic uncertainty and family formation is investigated. However, these studies might well suffer from ecological fallacies: It cannot be claimed that economically insecure individuals tend to postpone family formation if macro-economic uncertainties and marriage and fertility rates are negatively correlated. A first step to overcome this is to study family formation at the micro level, as we will do in this paper.

Second, we take both macro- and micro-level economic insecurities into account in explaining individual family formation decisions, which enables to disentangle the mechanism behind the impact of macro-level economic uncertainty. It is unclear whether a negative influence of high unemployment rates implies that unemployed people tend to postpone family formation or if this also (or only) holds for employed people. Here, we aim to determine to what extent the association between macroeconomic uncertainty and (postponement of) family formation is entirely explained by individual behaviour or whether there also is a contextual effect.

Third, using micro-level retrospective data has several advantages. It allows reconstructing the life course of individuals and their partner with regard to their employment and relationship history and the demographic transitions they make, so that causal inferences are possible about the assumed relationships. Event-history analyses are well-suited for this purpose. These data also enable to include partner characteristics that are considered relevant in explaining decisions on family formation, as they are usually made by both partners. In addition, family formation can be studied from a broad perspective and over a long time period by analysing first union (i.e. [un]married cohabitation), first marriage and first parenthood over the past decades. We thus analyse several stages in family formation in which postponement could occur.

Fourth, we study to what extent educational heterogeneity exists in macro- and micro-level effects of economic insecurity. As the opportunity costs of family formation differ under varying economic circumstances, it is quite likely that the lower- and higher educated respond differently if unemployment rates are high or if their labour market situation is precarious. So far, empirical studies paid limited attention to these differences.

\section{Macro-Level Developments in The Netherlands}

The Netherlands is a suitable case to test macro- and micro-level uncertainty explanations for family formation, as clear developments herein are visible, particularly after 1980. Figure 1 provides an overview of the most important developments between 1970 and 2000. Until the late 1970s, the average age at first marriage was almost 23 for Dutch women. Since the early 1980s, however, the 
average age steadily increased to 28.5 in 2000. Furthermore, the age at first childbirth steadily rose from 24 to 29 between 1970 and 2000. These developments imply a strong decrease in marriage rates and fertility. Other demographic developments shown in Fig. 1 are the rising divorce rates, the rise in unmarried cohabitation and the increase in the number of extramarital births.

Various cultural, structural and economic macro-level developments could explain the developments in family formation. Figure 2 presents them for The Netherlands between 1970 and 2000. The proportion of nonreligious people per year (i.e. secularisation) is used to indicate cultural developments. It strongly increased from almost 23 in 1970 to $40 \%$ in 2000 . Structural developments are indicated by economic globalisation, educational expansion (i.e. the gross enrolment ratio in tertiary education) and female labour market participation. Economic globalisation steadily increased since the 1970s. In 2000, The Netherlands was a highly globalised country: More than half of the population was enrolled in tertiary education. Female labour market participation rates fluctuated around $34 \%$ until the late 1980 s, increasing up to $52 \%$ in 2000 . Like in the rest of Europe, aggregate unemployment rates - as indicator for economic developments-were rather low until the early 1970s. Particularly in the early 1980s, unemployment rates were rising, especially among youth, but steadily dropping again from the mid-1980s until the early 1990s. Although the indicators presented might be considered as (too) rough for the specific changes that have actually occurred, they do provide a global picture of the processes that took place.

\section{Theory and Hypotheses}

The decision to marry or to start having children involves long-term investments of time, money and energy. Such decisions may be primarily based on romantic and emotional grounds, but being economically able to support a family is nevertheless an important condition (Oppenheimer 1988). Rindfuss and VandenHeuvel (1990) speak of an 'affordability clause', referring to the normative prescription that individuals should neither marry nor have children until they can afford to do so. The decision to start a family is thus partly based on future prospects of the involved costs and benefits. If economic or social uncertainties exist, any risk may be averted by postponement of family formation (McDonald 1996, 2002).

\subsection{Macro-Economic Uncertainty and Family Formation}

During an economic crisis, the possibilities and prospects of being economically stable enough to support a family are worse than in economically more prosperous times. Current labour market situation and prospects about this situation in the near future are the most important determinants of economic (in)stability, but strongly depend on the state of the economy. During a recession, even employees in stable jobs with permanent employment contracts are not safe from redundancies by companies, due to (the possible threat of) a company going bankrupt. The entire labour force may get more pessimistic about the current and/or future labour market 


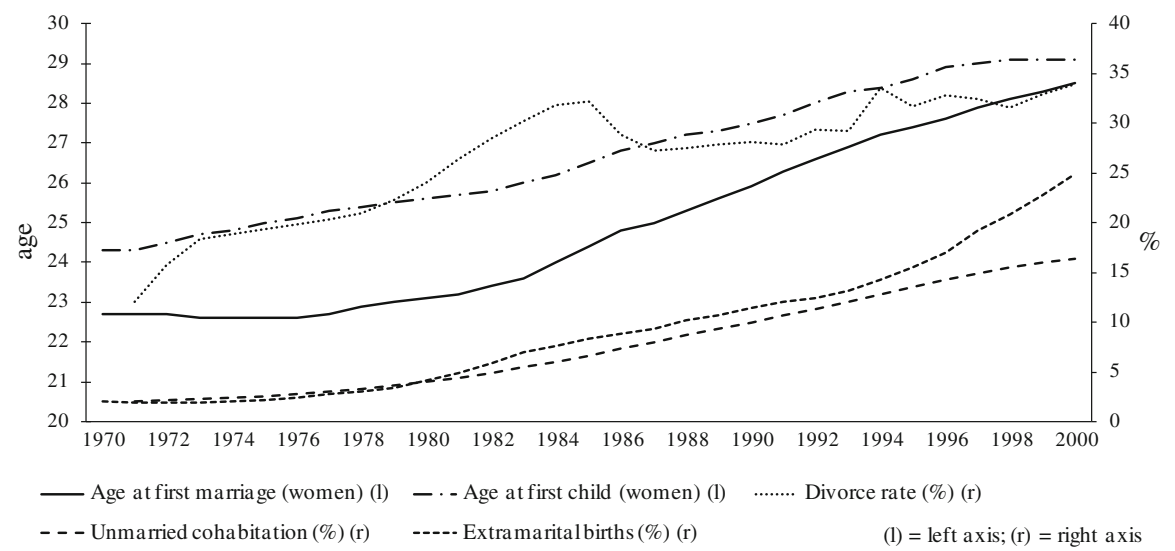

Fig. 1 Developments in family formation and dissolution in The Netherlands, 1970-2000. Source CBS (2013)

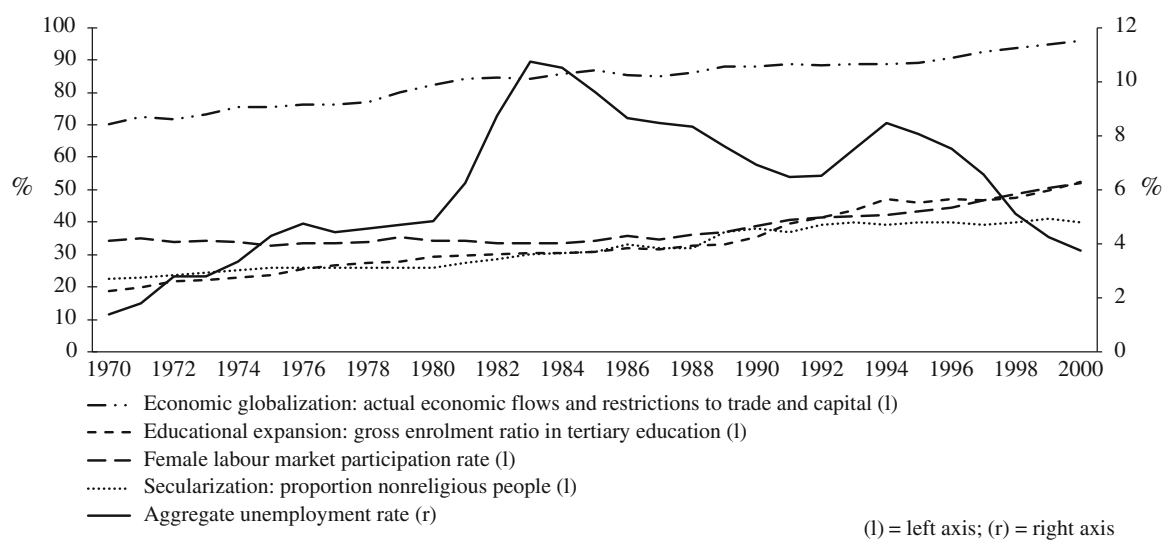

Fig. 2 Cultural, structural and macro-economic developments in The Netherlands, 1970-2000. Source CBS (2013), Dreher (2006), te Grotenhuis et al. (2012) and UIS (2012)

situation during a recession: One might (fear to) lose one's job without being able to find a new job again. In addition, wages are less likely to be adjusted to inflation or to increase due to promotion. Finally, chances of being promoted in one's current job are smaller in economic less prosperous times. This may prevent young people from completing family formation.

Some empirical evidence is already available. However, particularly the number of studies analysing the macro-level effect of economic insecurities by using microlevel data is scarce. For The Netherlands, de Beer (2012a) reports a positive correlation at the macro level between economic faith and marriage rates since the 1970s. With regard to fertility, a larger number of studies exists. Again for The Netherlands, de Beer (2009, 2012b) and Fokkema et al. (2008) show a positive macro-level association with economic faith. For other industrialised countries, empirical evidence was found for a negative association between unemployment 
rates and fertility, although the strength varies across countries and between different social groups (see Adsera 2011; Hoem 2000; Kravdal 2002; Neels 2010; Neels et al. 2012; Sobotka et al. 2011). We hypothesize that under less prosperous macro-economic conditions, men and women are less likely to start family formation $(\mathrm{H} 1)$.

\subsection{Individual Employment Insecurity and Family Formation}

The negative effect of macro-economic uncertainties is likely to be channelled through the experience of individual employment insecurity. The earlier mentioned economic crises in the 1970s and 1980s and the process of globalisation since the 1980s imply that a growing number of young people enter the labour market in temporary or on call employment (Mills and Blossfeld 2005; see also de Lange et al. 2012) or in unemployment. As economic recessions increase the individual likelihood of employment instability and insecurity, the above hypothesized macrolevel effect of economic uncertainties could (at least partly) be an effect of individually experienced employment insecurity.

Empirical evidence on the micro-level link between employment insecurity and family formation is still rather scarce. Research on the former Soviet Republics and Eastern European countries shows that the transition from a controlled economy to a market-based economy in the 1990s was followed by a sharp decline in birth rates. Increased individual uncertainty about future income was an important mediating factor for this relationship (Ranjan 1999). Published spin-offs from a workshop on Economic Uncertainty and Family Dynamics in July 2009 in Berlin (Kreyenfeld et al. 2012) reveal that in several countries, like Germany, France, Sweden and Israel, employment instability seems to lead to postponement of marriage or parenthood, mainly or only among men. In the United Kingdom and Italy, evidence was found for unemployed women showing higher fertility rates (Kreyenfeld et al. 2012). Also Kreyenfeld (2010) shows a similar result for lower educated German women, although higher educated women do indeed postpone parenthood. Finally, Hofmann and Hohmeyer (2013) demonstrate that strong economic concerns, subjectively measured, among German women reduce fertility.

The literature puts forward various arguments for a negative effect of individual employment insecurity on the timing of family formation, which differ for men and women. In industrialised countries like The Netherlands, men are usually still responsible for the family income (Becker 1981). Particularly for men, an insecure and instable labour market position hampers providing a stable family income (Oppenheimer 1988; Oppenheimer et al. 1997; Schmitt 2008). Furthermore, men in unstable jobs are considered less attractive as marriage partners and fathers by women, reducing their chances of a stable relationship (Oppenheimer 1988).

Despite the still dominant position of men, women's socioeconomic role outside and within the family has gained much in importance (Brewster and Rindfuss 2000; Kreyenfeld 2010; Oppenheimer 1994). On average, women became more focused on making a career after leaving school. Once they complete family formation, they are no longer expected to leave the labour market to start a 'career' as housewife and mother. Over the years, women's employment has thus become a barrier for 
family formation (Kreyenfeld 2010). Similarly, women's unemployment provides reasons for having a child, due to lower opportunity costs (Butz and Ward 1979). So why would employment insecurity then prevent women from starting a family? One important reason is that a stable employment situation for both the man and the woman has become a prerequisite for family formation (Kreyenfeld et al. 2012, p. 843). Societies have made accommodations in the light of the growing importance of dual-breadwinner families (Kreyenfeld et al. 2012). As the financial ability of running a household increasingly depends on the combined income of both partners, economic insecurity among women may also lead to postponement of family formation. It could also be argued that women in insecure labour market situations might fear that temporarily withdrawing from the labour market due to motherhood hinders finding a stable job when they wish to re-enter. To meet their aspirations for professional activity, women might therefore prefer to be in stable employment before making the transition into motherhood.

Finally, Oppenheimer (1988) suggests that, and this holds for both men and women, also the social consequences of insecure work can explain postponement of family formation. Lacking an established labour market position, for temporarily and unemployment people it is still uncertain what kind of job they will have in the near future. Moreover, it may be difficult for them to judge the exact investments they need to make in terms of time and efforts. Some jobs, require much travel time, have irregular working schedules, or involve high working pressure, which comes at the expense of the amount of time and energy available for family life. These kinds of uncertainties are likely to delay family formation decisions.

Summarising the above-mentioned empirical evidence and theoretical argumentation, we expect that men and women experiencing employment insecurity are less likely to start family formation, compared to men and women in more stable employment positions (H2).

\subsection{The Effect of Employment Insecurity Under Varying Macro-Economic Conditions}

Although it is argued that labour market insecurities lead to postponement of family formation, the actual perception of experiencing economic insecurity may vary under different macro-economic circumstances. In times when labour market prospects are good, temporarily employed or unemployed individuals might still be optimistic about their labour market situation in the near future, despite their current insecure situation. The decision to start a family might then be less strongly postponed or perhaps not postponed at all. Conversely, in economically less advantageous times, the perception of economic insecurity could be reinforced, which makes people more reluctant to take important decisions on family formation and carry these responsibilities in the longer term. We expect that men and women experiencing employment insecurity are less likely to start family formation if macro-economic conditions are less prosperous (H3). 


\subsection{Differentiation of the Impact of Economic Insecurities by Educational Qualifications}

It is likely that lower and higher educated individuals do not equally respond to employment insecurity. Furthermore, one can argue that the educationally heterogeneous effect of economic insecurity on family formation is opposite for men and women (Liefbroer and Corijn 1999; Sobotka et al. 2011). These expectations can be derived from rational choice theory based on Becker's New Home Economics (Becker 1981), assuming that family formation involves high costs.

For men, it is hypothesized that the negative effects of macro-economic adversity (H4a) and employment insecurity (H5a) on family formation pertain less to higher educated, as a higher educational level is generally associated with a higher income and better labour market prospects. Since men are still mainly responsible for the family income in The Netherlands (Liefbroer and Corijn 1999; Visser 2002), decisions on family formation may be mainly based on the income level of the male partner. Higher educated men are expected to bear the high costs associated with family formation more easily than lower educated men. Although both macroeconomic uncertainty and employment may not directly involve a better financial situation for the higher educated, still their future labour market and income prospects will be more favourable, compared to economically more insecure lower educated people. This also makes higher educated men more attractive in the 'marriage market', compared to lower educated men (Kalmijn 1991; Oppenheimer 1988). Higher educated men are thus expected to be less restricted by labour market insecurities in their family intentions.

For women we expect that the negative effects of macro-economic adversity $(\mathrm{H} 4 \mathrm{~b})$ and employment insecurity (H5b) on family formation particularly pertain to the higher educated, as a higher level of education involves higher opportunity costs (Liefbroer and Corijn 1999; Oppenheimer 1988). Starting (and supporting) a family requires a lot of time that could also be invested in paid labour. The amount of foregone income is higher for women with higher qualifications. Furthermore, higher educated women may consider a reduction of working hours or resignation for the sake of family formation more often as a waste of their education, compared to lower educated women. Even though women in insecure labour market situations may have not so much to lose, also future expectations regarding labour market participation play a role in the decision to start a family. These expectations are better for higher educated women than for lower educated ones. For lower educated women, fulfilling the role of (house)wife or mother could even be a strategy to reduce or compensate insecurities in the labour market. Finally, differences in attitudes towards family formation could explain diverging postponement behaviour of higher and lower educated women. Higher educated women usually have more liberal and less traditional attitudes with regard to family formation than lower educated women do (Liefbroer and Merz 2009). This could be an additional reason why higher educated women in insecure labour market situations postpone family formation to a stronger extent than comparable lower educated women. 


\section{Data and Method}

\subsection{Data and Sample Selection}

Our research questions ask for detailed life history information complemented with macro-level data, which allows investigating how macro-economic and individual employment insecurity are causally related to family formation. The Family Survey Dutch Population (FSDP) (in Dutch: 'Familie-enquête Nederlandse Bevolking') is a five-yearly large scale retrospective survey registering the life course of individuals and their partners with regard to different domains as education, labour market, partnerships and children. We use data collected in 2000 (de Graaf et al. 2000). ${ }^{1}$ The sample procedure is two-step stratified: First, a random sample of 67 municipalities was drawn and second, a random sample of respondents within these municipalities. In total, 1561 respondents (primary respondents and partners) were interviewed between April 2000 and October 2000. The first part of the interview concerned Computer Assisted Personal Interviewing, and the second part consisted of a written questionnaire, usually completed while the partner was being interviewed. Due to the method of retrospective questioning, respondents' characteristics and behaviour can be observed far before 2000. This enables to cover an extensive period in time in which changes in family formation are expected to occur. ${ }^{2}$ This retrospective information has been collected by asking respondents when a certain event started and when it ended. The dates of recurring events (such as education or jobs) were summarised in a scheme with help of the interviewer, to ensure that dates to not overlap or that information on specific periods is missing.

The analytical sample is restricted to heterosexual couples of which both partners indicated to be each other's first serious partner in a relationship that started not before 1970, and being maximally 45 years old. We then created a person-month file, in which respondents have been followed from month to month since the start of their relationship, until the moment the events of our interest (i.e. first union, marriage or parenthood) occur. For each respondent, the first record in the data set is the first month of the relationship. For every month a respondent is observed, an additional record is added. Based on the dates of events reported by the respondents, the status of a specific variable is then 'calculated', resulting in either time-constant or time-varying variables. Respondents who have not experienced the event before the moment of interview (in 2000) are treated as right censored. These selections

\footnotetext{
${ }^{1}$ Although five waves of the FSDP are currently available, we could only use the 2000 wave, containing detailed information on the full employment history (including information on temporary employment) of individuals and their partners, which is lacking in the other waves.

2 This method of data collection, however, could involve a problem of what is called 'recall bias'. This implies that especially couples who began their relationship at the start of the investigated period (i.e. 1970s) have to report on employment, partnership and fertility histories of a long time ago, which might lead to unreliable information. We would like to emphasise, however, that these also concern important life events that most individuals might very well remember, even after many years. In addition, this only applies to the group of respondents, who have actually started their relationship such a long time ago and for the earliest years of their relationship. Moreover, we have no reason to assume that possible errors within this respect would be systematic errors, and therefore we do not expect that our findings are biased by this.
} 
result in an analytical sample of 729 respondents: 365 male partners and 364 female partners.

\subsection{Dependent Variables}

The first indicator of family formation is the moment of starting the first union, i.e., the moment partners start living together in one household, either married or unmarried. 352 men and 352 women started a first union before the moment of interview, $45 \%$ in marriage and $55 \%$ in cohabitation. The second indicator is the moment of first marriage. This dependent variable refers to the month in which an individual makes the transition from being unmarried to being married for the first time. 319 men and 319 women married before the moment of interview. The third indicator refers to the moment of becoming a parent for the first time. To determine this moment, the date of conception of the first child is calculated by subtracting nine months from the date of birth of the first child. This usually is considered as the best proxy for the moment people 'decide' to start having children. 287 men and 286 women had their first child before the moment of interview.

\subsection{Macro-Level Independent Variables and Control Variables}

Macro-economic conditions are measured by the aggregate unemployment rate, provided by Statistics Netherlands (CBS 2013). These numbers vary yearly, implying that every month within the same year has been assigned the same value. They are measured 1 year ahead, which means that if the likelihood to experience the event in year $(t)$ is being estimated, the measurement of the unemployment rate refers to $(t-1)$ year, thus covering a period from 1969 to 1999. This variable has been rescaled into a variable ranging from 0 to 1 and subsequently mean-centred.

At the macro level, the empirical models are controlled for the degree of modernization in a certain year, to exclude cultural and structural explanations for postponement of family formation. This variable is also measured 1 year prior to the measurement of the dependent variables. It is the average of the separately rescaled measurements of secularisation [i.e. proportion of nonreligious people, based on a question asking if one considers him/her self as being religious (te Grotenhuis et al. 2012)], educational expansion [i.e. gross enrolment ratio in tertiary education (UIS 2012)] and economic globalisation [i.e. KOF Index of Globalisation, which is a scale of the weights of different indicators referring to actual economic flows and restrictions to trade and capital (Dreher 2006)]. The indicator of modernization is subsequently mean-centred.

\subsection{Micro-Level Independent Variables and Control Variables}

Employment (in)security is measured time-varyingly by an individual's labour market situation and distinguishes between permanent employment [i.e. a permanent employment contract or a temporary employment contract with prospect of a permanent contract (reference category)], temporary employment (i.e. a temporary employment contract without prospect of a permanent contract, or on call 
employment), unemployment (self-reported, during the period in-between jobs) and other situation (including being in education, inactive, self-employed or unknown). Level of education is measured in three categories: low, intermediate and high. ${ }^{3}$ Lower educated people are the reference category.

As control variables, sex (reference is man), year of birth (for men minus 1939 and for women minus 1942), age (minus 15) and age (minus 15) squared are included. Additionally, the statistical models are controlled for religiosity (i.e. being religious versus nonreligious), ${ }^{4}$ marital status [i.e. unmarried cohabitation (only included in the analyses of the first marriage and parenthood) or married cohabitation (only included in the analysis of parenthood) versus no cohabitation], the number of weekly working hours (varying from 0 to 60), partner's level of education (i.e. medium or high versus low) and partner's labour market situation (i.e. temporary employment, unemployment, or other versus permanent employment). Except for sex and year of birth, all individual-level control variables are time-varying.

An overview of all variables in the person-month file included in the analysis is presented in Table 1.

\subsection{Method and Model Building}

We use event-history analysis to test our hypotheses. Piecewise-constant exponential models (PCE) have been applied to estimate the effects of the explanatory variables on the monthly hazard rates of experiencing the transition into first union, first marriage and parenthood (Blossfeld and Rohwer 2002), after the start of the relationship.

For each dependent variable, five empirical models have been estimated; the last two models only for men and women separately. In the first model, the main effects of the unemployment rate and level of education are estimated, controlled for level of modernization, (sex, ) year of birth, age, age squared and religiosity. Based on this model, we can assess the impact of macro-economic uncertainty on postponement of family formation (H1). In the second model, the individual's labour market situation is added, controlled for the number of working hours and both level of education and labour market situation of the partner. Based on this model's estimations, the hypothesis is tested on the impact of individual employment insecurity (H2). In Model 3, the effects of the interaction terms between labour market situation and unemployment rate have been estimated, which provides the estimates to test to what degree postponement of family formation due to employment insecurity is strengthened by macro-economic uncertainties (H3). In the final two models, the interaction terms between (macro-)economic insecurities and level of education have been estimated (i.e. in Model 4, the interaction between unemployment rate and level of education and, in Model 5, the interaction between labour market situation and level of education). From these models, it can be

\footnotetext{
${ }^{3}$ The category 'low education' consists of people with $\mathrm{BO}$ and LBO; 'intermediate education' refers to people with MAVO, HAVO, VWO and MBO and 'high education' is composed of people with HBO, $\mathrm{WO}$ and $\mathrm{WO}+$.

${ }^{4}$ The correlation between this individual-level variable and the yearly measured modernization rate is 0.090 , which implies that these variables are not collinear.
} 
Table 1 Descriptive statistics of the dependent and independent variables (\# episodes men $=72,650$; \# episodes women $=74,473$ )

\begin{tabular}{|c|c|c|c|c|c|c|}
\hline & \multicolumn{2}{|l|}{ Range } & \multicolumn{2}{|l|}{ Mean } & \multicolumn{2}{|l|}{ SD } \\
\hline & Men & Women & Men & Women & Men & Women \\
\hline \multicolumn{7}{|l|}{ Dependent variables } \\
\hline Transition into first union & \multicolumn{2}{|c|}{$0 / 1$} & 0.0048 & 0.0047 & 0.0694 & 0.0686 \\
\hline Transition into first marriage & \multicolumn{2}{|c|}{$0 / 1$} & 0.0044 & 0.0043 & 0.0661 & 0.0653 \\
\hline Transition into first child & \multicolumn{2}{|c|}{$0 / 1$} & 0.0040 & 0.0038 & 0.0627 & 0.0619 \\
\hline \multicolumn{7}{|l|}{ Independent variables } \\
\hline Year of birth & 1939-1979 & $1942-1980$ & 1957 & 1959 & 7 & 7 \\
\hline Age & \multicolumn{2}{|c|}{$15-45$} & 31 & 29 & 7 & 7 \\
\hline \multicolumn{7}{|l|}{ Religiosity } \\
\hline Nonreligious & \multicolumn{2}{|c|}{$0 / 1$} & 0.54 & 0.51 & & \\
\hline Religious & \multicolumn{2}{|c|}{$0 / 1$} & 0.46 & 0.49 & & \\
\hline \multicolumn{7}{|l|}{ Level of education ${ }^{a}$} \\
\hline Low & \multicolumn{2}{|c|}{$0 / 1$} & 0.29 & 0.26 & & \\
\hline Intermediate & \multicolumn{2}{|c|}{$0 / 1$} & 0.47 & 0.55 & & \\
\hline High & \multicolumn{2}{|c|}{$0 / 1$} & 0.24 & 0.19 & & \\
\hline \multicolumn{7}{|l|}{ Employment situation $^{\mathrm{a}}$} \\
\hline Permanent employment & \multicolumn{2}{|c|}{$0 / 1$} & 0.74 & 0.49 & & \\
\hline Temporary employment & \multicolumn{2}{|c|}{$0 / 1$} & 0.04 & 0.04 & & \\
\hline Unemployment & \multicolumn{2}{|c|}{$0 / 1$} & 0.01 & 0.02 & & \\
\hline Other & \multicolumn{2}{|c|}{$0 / 1$} & 0.21 & 0.45 & & \\
\hline Working hours & \multicolumn{2}{|c|}{$0-60$} & 33 & 17 & 17 & 17 \\
\hline Unemployment rate $^{\mathrm{b}}$ & \multicolumn{2}{|c|}{-0.48 to 0.52} & 0.13 & 0.12 & 0.21 & 0.21 \\
\hline Modernization & \multicolumn{2}{|c|}{-0.46 to 0.45} & 0.11 & 0.12 & 0.21 & 0.21 \\
\hline
\end{tabular}

Source Family Survey Dutch Population 2000

a See for the statistics of the partner variables the statistics of the opposite sex

b Transformed variable: original values range from 1.39 to $10.72 \%$

derived to what extent the degree of postponement of family formation due to labour market insecurities varies among men and women with different educational qualifications (H4ab and H5ab).

\section{Results}

\subsection{Transition into First Union}

The results of the piecewise-constant exponential models with regard to the transition into the first union are presented in Table 2. Model 1 shows that the aggregate unemployment rate negatively affects the likelihood to start a first union $[\operatorname{Exp}(B)=0.41]$, implying that young people are less likely to start (un)married 
cohabitation when macro-economic conditions are bad, supporting the first hypothesis.

From Model 2, it can be derived that the negative effect of the unemployment rate hardly decreases after taking the individual's and partner's labour market situation into account $[\operatorname{Exp}(B)=0.45]$, which implies that the negative effect of macro-economic uncertainties is not channelled through individual employment insecurities, but that it exists beyond and primarily independent of that. With regard to the effect of the individual's labour market situation, however, we find that this is absent, although partner's temporary employment appears to increase the likelihood of a first union (effects not shown). When we look at the gender-specific results that are available on request, we find that this effect pertains to men with a female partner in temporary employment. Similarly, we find that for women, a temporary job increases the likelihood of a first union. These findings suggest that if women are in an insecure labour market situation, they do not tend to postpone but instead 'hurry' the first union. With regard to our hypotheses, we can conclude that individual employment insecurity does not decrease the likelihood of the first union (H2), neither does it explain the effect of macro-economic uncertainties.

To examine whether employment insecurity differently affects the likelihood of a first union under varying macro-economic circumstances, the interaction terms between both variables are added in Model 3. From the joint model for men and women, it appears that the main effect of (individual) unemployment is positive and significant at the $90 \%$ confidence level $[\operatorname{Exp}(B)=1.89]$. As we mean-centred the macro-level variables, this is the effect of unemployment when the aggregate unemployment rate is average. None of the interaction terms are significant, implying that this effect does not differ under varying macro-economic conditions. However, comparing Model 3 for men and women (results available on request) does reveal that the positive effect of unemployment pertains to men and that a negative interaction exists with the unemployment rate. So, under average aggregate unemployment, unemployed men do 'hurry' the first union, but as unemployment grows this effect turns negative and men do postpone the first union, like we expected. This interaction effect does support hypothesis 3 for men, although the main effect is not in the expected direction. For women, we still find a positive effect of temporary employment in Model 3 that does not vary among different unemployment rates. So for women, the third hypothesis is not supported by our findings.

In Models 4 and 5, we test the gender-specific hypotheses on the educationally heterogeneous effect of macro-economic and employment uncertainty. For men, we find no educational differences in the negative effect of the unemployment rate on the first union (Model 4). For women, conversely, only a negative effect is found of the unemployment rate for intermediate educated women, while we particularly expected an effect among higher educated. Both findings do not support $\mathrm{H} 4 \mathrm{a}$ and H4b. With regard to the interaction between employment insecurity and level of education, Model 5 shows some clear but unexpected results for men: Lower educated men in unemployment are more likely to start a first union compared to lower educated permanently employed men $[\operatorname{Exp}(B)=12.59]$, but for intermediate educated men this positive effect of unemployment is much smaller and almost 


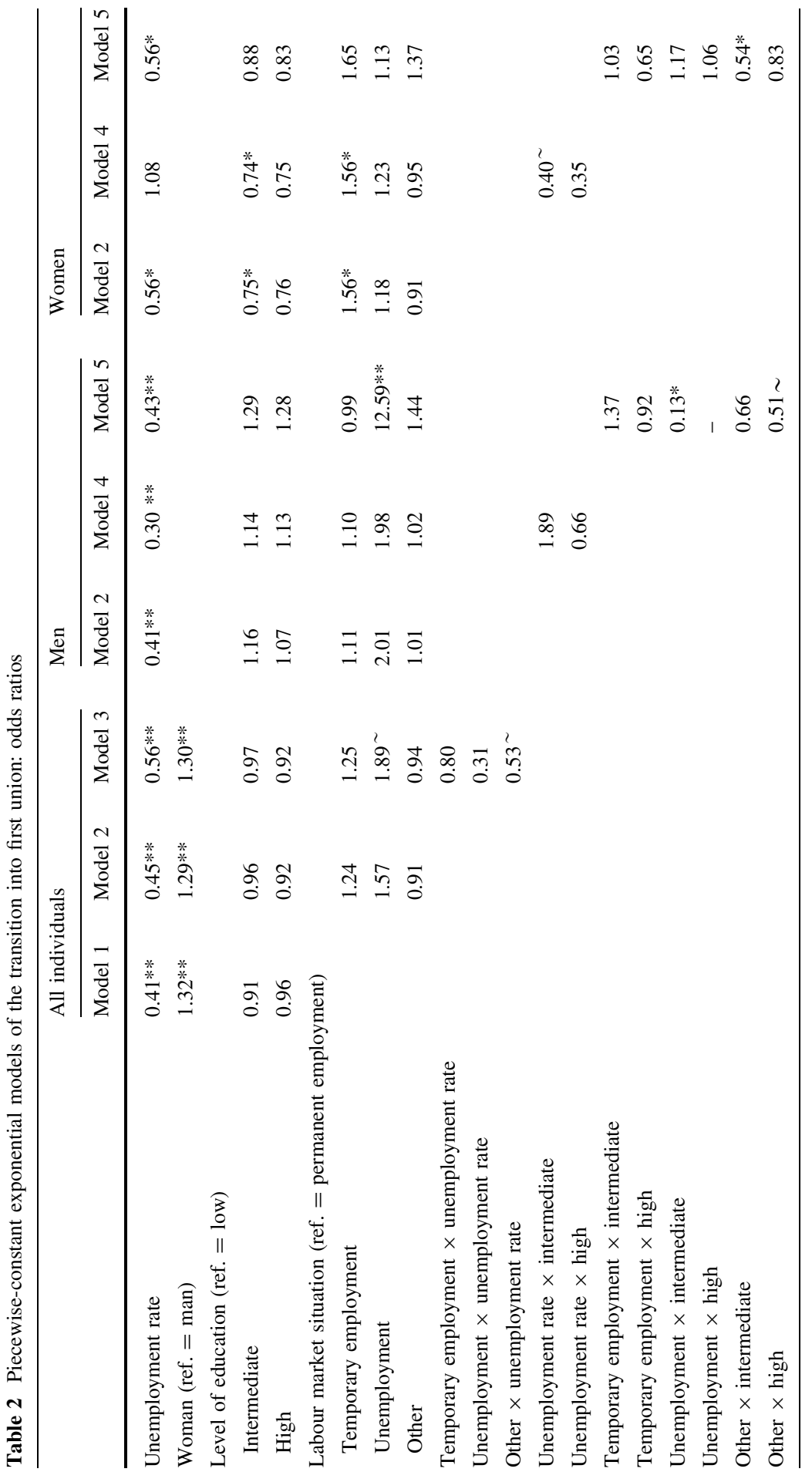

\section{袋 Springer}




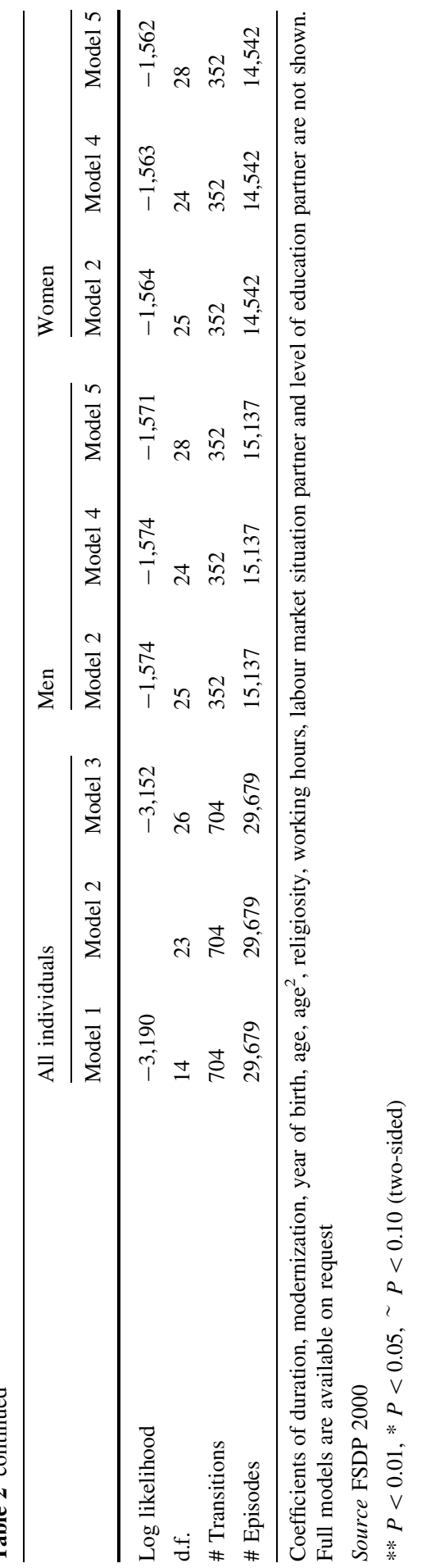


absent $[\operatorname{Exp}(B)=1.64]$. This result rejects H5a. Also H5b finds no support, as for women none of the interaction coefficients between employment insecurity and level of education is significant. We would like to note, however, that we have to be cautious in interpreting the results of the interaction models. Interacting temporary employment and unemployment with level of education results in small numbers of cases. Therefore, the estimates of the interaction terms might be less stable and reliable.

\subsection{Transition into First Marriage}

In Table 3, the results are presented with regard to the transition into the first marriage. From Model 1, it can be derived that when macro-economic conditions deteriorate, young people are less likely to start the first marriage $[\operatorname{Exp}(B)=0.35]$, supporting the first hypothesis (H1). The gender-specific models (available on request) show that this particularly applies to women, though also to men. This gender difference in the strength of the effect is opposite to what we found for the transition into the first union. Model 2 shows a negative effect of a temporarily employed partner (effects not shown), but from the gender-specific models we learn that this effect is only found among women with a temporarily employed man. Indeed for men we find a negative effect of their own temporary employment on the first marriage $[\operatorname{Exp}(B)=0.58]$. So, men in temporary jobs seem to postpone the first marriage, compared to men with a stable, permanent job. This finding corroborates the second hypothesis. Comparing the effects of macro-economic and employment insecurity in Model 2 with the first model furthermore shows that the effect of macro-economic uncertainties on the first marriage is not explained by individual employment insecurity. Both types of uncertainties have their own independent effect.

Contrary to our expectations, interacting macro- and micro-level insecurities does not strengthen postponement of the first marriage, but increases the likelihood to marry for the first time. Model 3 demonstrates that when the unemployment rate is average, people with temporary jobs are less likely to marry $[\operatorname{Exp}(B)=0.64]$, while during an economic recession the likelihood to marry is actually bigger, compared to people with a permanent job $[\operatorname{Exp}(B)=2.80]$. Looking at the genderspecific models (available on request), this rather unexpected finding that rejects $\mathrm{H} 3$ seems to apply only to women. It suggests that women search for financial security through marriage, when economic insecurities accumulate, which is perhaps not as unexpected as it initially seemed.

The results in the last two models show whether the impact of economic insecurities on the timing of the first marriage varies among people with different educational credentials. For both men and women, the results in Model 4 are clear: None of the interaction terms between educational level and economic insecurities are significant, which implies that our data cannot support the idea that lower and higher educated individuals respond differently to macro-economic uncertainties (H4a and H4b). In Model 5 for men, we find, however, that the effect of a temporary job on the likelihood to first marry is positive for highly educated men. Although we hypothesized that higher educated men would be better able to support a family, we 


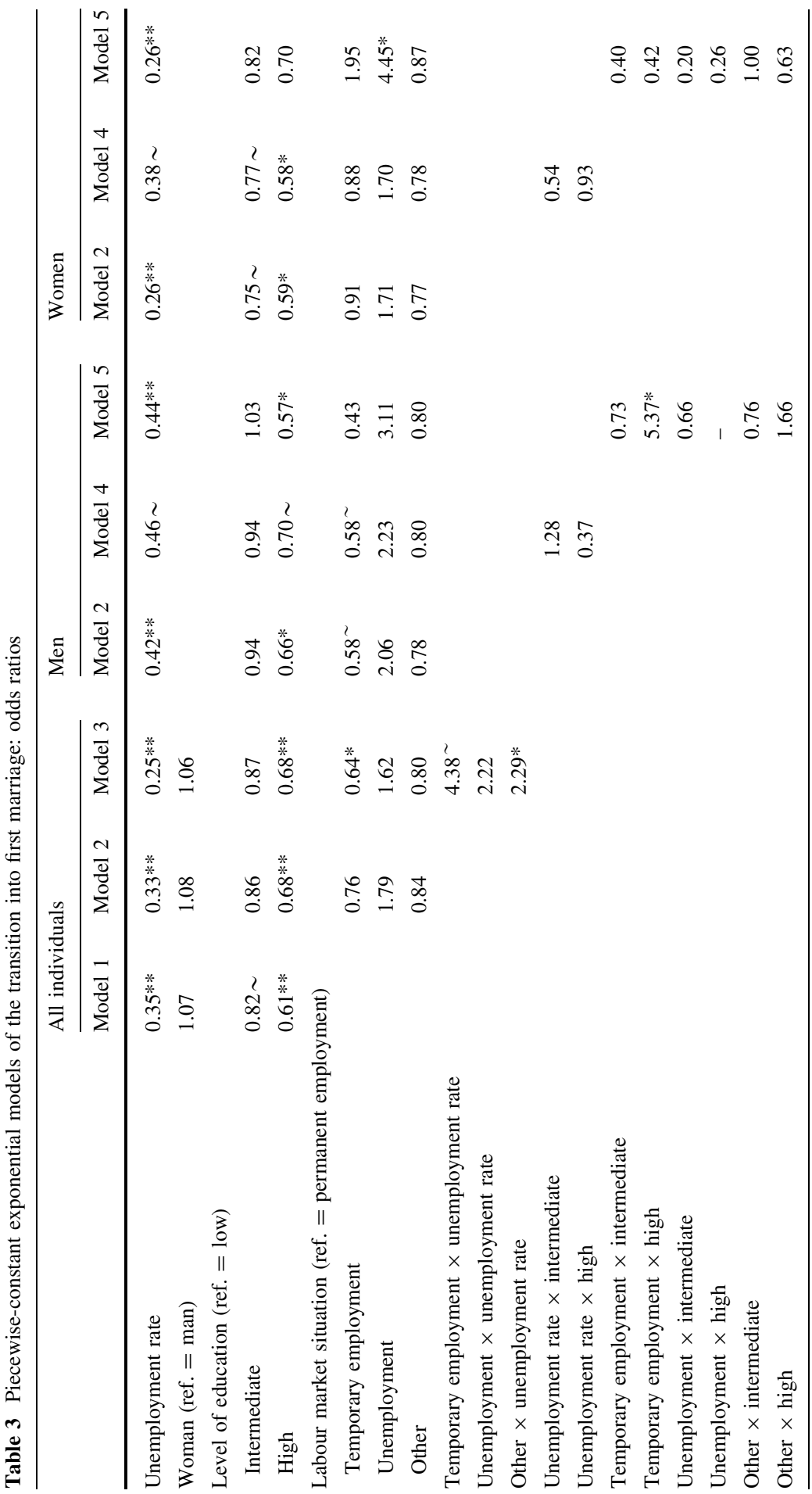




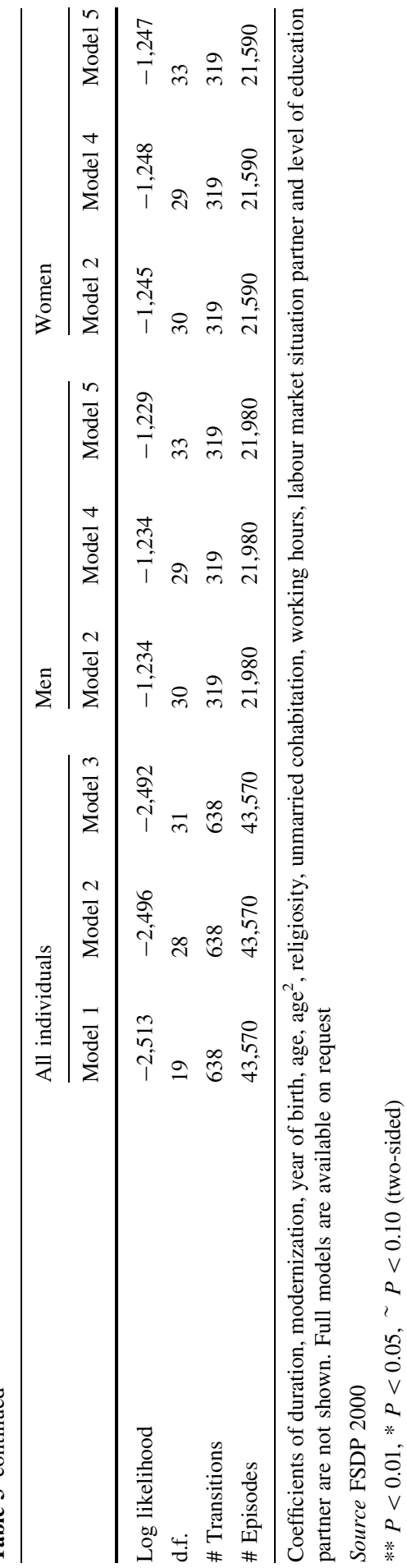


did not expect that a temporary job would be positively related to the first marriage, rejecting H5a. For women, the interaction terms show no significance in Model 5, rejecting also $\mathrm{H} 5 \mathrm{~b}$. In this model, we do find, however, that unemployed women are more likely to marry compared to permanently employed women. Again, this suggests that women search for financial security through marriage if they lack security in their career. Once again, we would like to note that we have to be cautious in interpreting the results of the interaction models due to a possible lack of statistical power.

\subsection{Transition into Parenthood}

Finally, the results with regard to the transition into parenthood are summarised in Table 4. In contrast to the results regarding first union and first marriage, macroeconomic uncertainties do not seem to affect the decision to start having children, neither among men nor among women. This finding rejects our first hypothesis. Also the second hypothesis, regarding individual employment insecurity is not supported. Model 2 shows that neither temporary employment nor unemployment significantly affects the timing of the first childbirth. Fertility decisions hence do not seem to be based on economic arguments. In Model 3, we do find a positive interaction between temporary employment and the unemployment rate. The gender-specific models (available on request) show that this effect is only significant for men and implies that as aggregate unemployment is higher, men in temporary jobs are more likely to become a father $[\operatorname{Exp}(B)=5.93]$. This finding is rather unexpected and does not corroborate $\mathrm{H} 3$. An explanation for this effect might be that during an economic crisis the reason for having a temporary job might be searched in the unfavourable economic circumstances. It could be that such men expect to find a better, more stable job when labour market perspectives improve and that the temporary job provides a perfect opportunity to start a family. Finally, according to Models 4 and 5, fertility intentions of lower and higher educated young people are not differentially affected by labour market insecurities. So, in line with the findings for the timing of the first union and marriage, we have to reject H4ab and H5ab.

\section{Conclusion and Discussion}

Family dynamics have considerably changed since the 1970s. In this paper, we studied to what extent postponement of the first union, marriage and parenthoodbetween 1970 and 2000 in The Netherlands - can be explained by macro-economic and individual employment insecurities. We found that as the aggregate unemployment rate is higher, all individuals (both men and women) postpone the first union and marriage, but not the first child. Macro-economic uncertainty does clearly affect the decision to share a household together, either married or not, but once living together, the wish to have a child is not postponed, even if the economic circumstances are not so prosperous. This result may be understood by the fact that having a child is a very important decision in peoples' lives and cannot be postponed indefinitely due to fertility reasons. Additionally, in a welfare-state like 


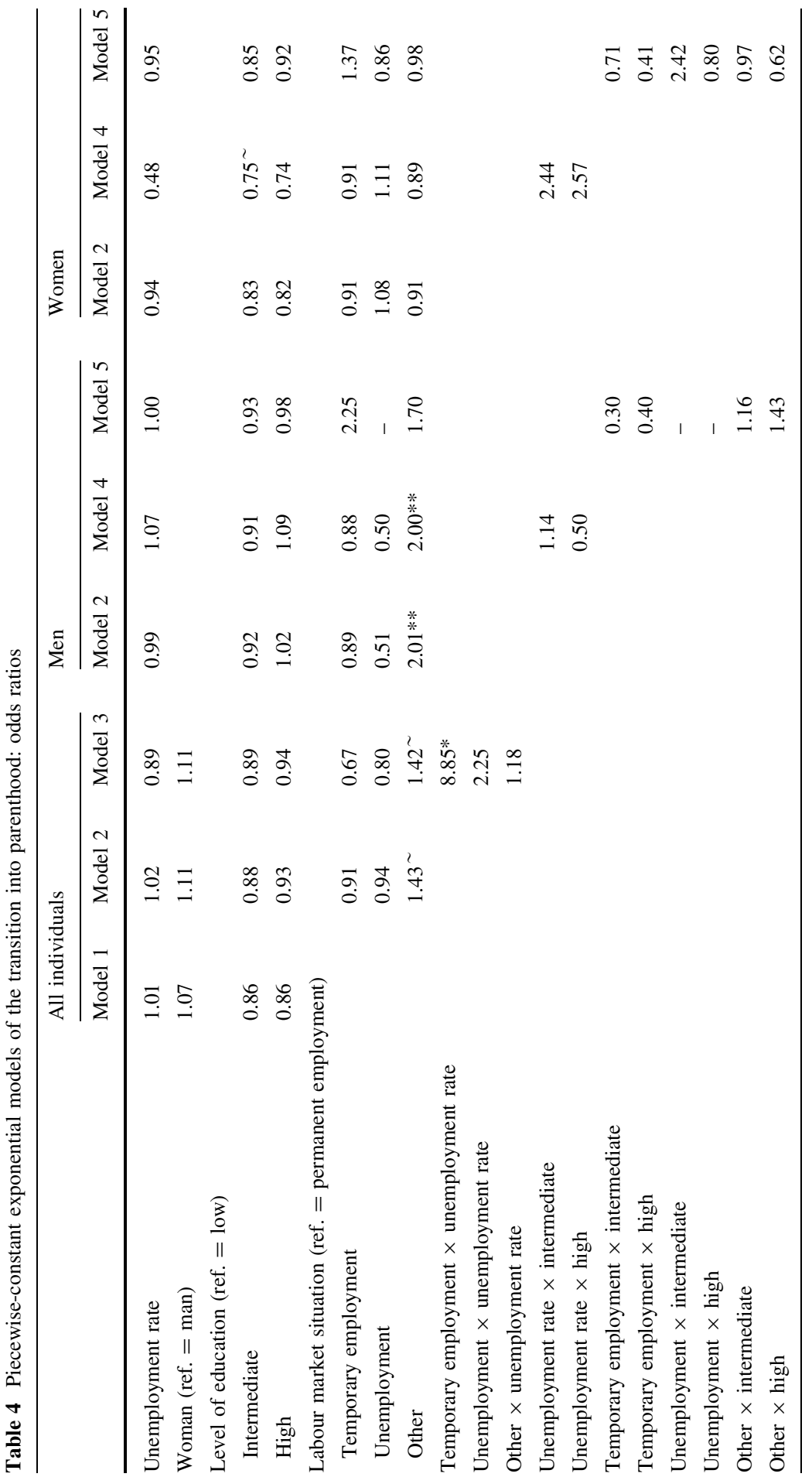

\section{글 Springer}




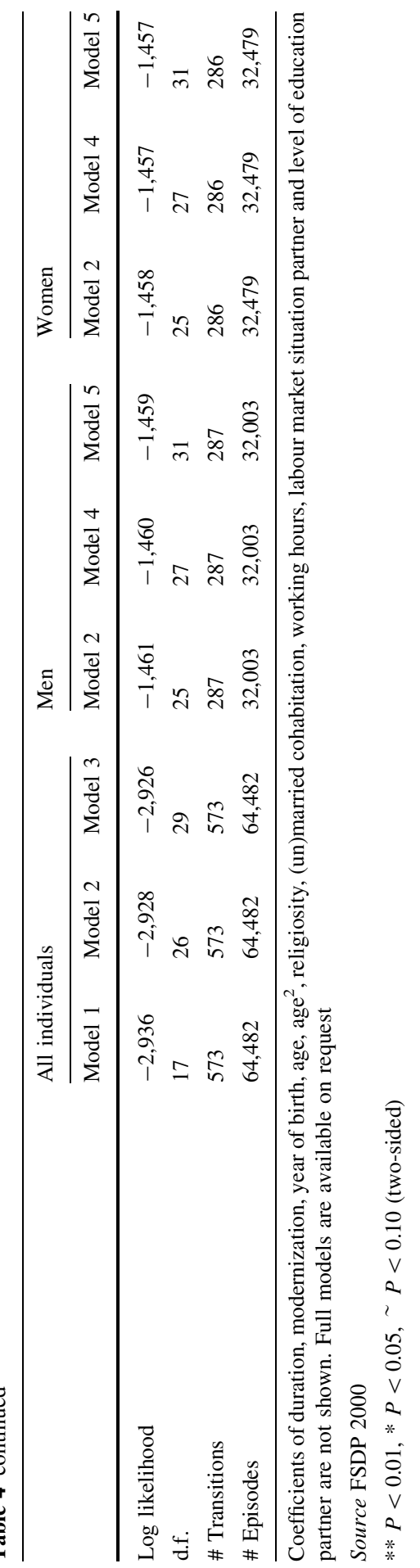


The Netherlands, the government usually protects households from economic deprivation, so they are generally provided with the necessary means to raise a family.

The negative effect of macro-economic uncertainty on the first union and marriage is not channelled through the experience of temporary employment or unemployment. This implies that also people with a stable job are discouraged to start a family under adverse economic circumstances. Individual's employment insecurity itself is no reason for postponing long-term family commitments. With regard to a possible reinforcing effect of macro- and micro-level uncertainties on family formation, the empirical support was scarce and not in the expected direction. It cannot be concluded that people in insecure employment situations particularly postpone family formation in times of economic uncertainty. Finally, our findings also lack substantial support for the conclusion that men and women with varying educational levels are differently affected by macro- and micro-level uncertainties in their decisions regarding family formation. As we have pointed out earlier, this could be due to a lack of sufficient statistical power. Future research should address these possible differential effects of economic insecurities for lower and higher educated using larger analytical samples.

What are the implications of our findings? The main finding in this paper is that economic conditions determine decisions regarding unmarried cohabitation or marriage in The Netherlands, but not regarding parenthood, at least not of the first child. Depending on how long couples postpone marriage during an economic recession, this implies that the time between marriage and becoming a parent decreases in uncertain times or even reverses, resulting in a growth in non-marital fertility. Whereas in the past it was not socially accepted to become a parent without being married, extramarital births became more widespread since the 1980s in particular, as Fig. 1 showed, which is also the period in which the economy reached its nadir. This figure also showed that the difference in mean age at first marriage and first child decreased since the 1980s, as the age at first marriage increased faster than the age at first childbirth. Based on our findings, we can conclude that macroeconomic uncertainties are an important factor contributing to these changes in family dynamics in the last decades and should therefore be studied in future research, in addition to the more traditional explanations for developments in family formation. Within this respect, it would also be interesting to study the period after 2000, including a mild recession around 2003 and the bigger economic recession starting in 2008, which has still not finished yet.

Based on our finding that micro-level insecurities do hardly interfere with decisions regarding family formation, the belief grows that spells of temporary employment and unemployment in the early career are not perceived as economically insecure as outsiders may assume. This is a positive message, in light of the ongoing process of labour market flexibilization in industrialised countries like The Netherlands. Our results do not give rise to the idea that developments in family formation in The Netherlands (continue to) stagnate due to an increasing share of precarious employment among people at a reproductive age.

We would also like to comment upon the research questions presented here. These questions assume that family formation is a desired outcome for every 
individual and that postponement of marriage and parenthood are due to macro- or micro-level uncertainties. It is not taken into account here that people may consciously decide to live alone, be unmarried or be childless, even when they are in a serious relationship. We assume, however, that our conclusions are not biased by these possibilities, since it most likely concerns just a small group of people and no correlation is assumed between being voluntarily unmarried or childless and experiencing labour market insecurity.

Finally, the effects of micro-level insecurities on family formation have been studied by examining the labour market situation of both partners separately. It could be argued, however, that it is especially the combination of two insecure employment positions within a household that creates uncertainties leading to postponement of family formation. Future research could focus on the cumulative effect of employment insecurities within a household, which was not possible in this research due to data limitations.

\section{References}

Adsera, A. (2011). The interplay of employment uncertainty and education in explaining second births in Europe. Demographic Research, 25, 513-844.

Becker, G. S. (1981). A treatise on the family. Cambridge: Harvard University Press.

Bell, D. (1976). The coming of post-industrial society: A venture in social forecasting. New York: Basic Books.

Blanchard, O. (2006). European unemployment: The evolution of facts and ideas. Economic Policy, 21(45), 5-59.

Blossfeld, H.-P., \& Rohwer, G. (2002). Techniques of event history modeling. New approaches to causal analysis (2nd ed.). Hillsdale, NJ: Erlbaum.

Brewster, K. L., \& Rindfuss, R. R. (2000). Fertility and women's employment in industrialized nations. Annual Review of Sociology, 26, 271-296.

Butz, W. P., \& Ward, M. P. (1979). The emergence of countercyclical U.S. fertility. The American Economic Review, 69(3), 318-328.

CBS. (2013). Statline. Den Haag: Centraal Bureau voor de, Statistiek. Retrieved May 29, 2013, from http://statline.cbs.nl.

de Beer, J. (2009). Crisis en vruchtbaarheid in Nederland. Demos, 25(9), 4.

de Beer, J. (2012a). Trouwen en scheiden in tijden van voor- en tegenspoed. Demos, 28(5), 1-5.

de Beer, J. (2012b). Crisis in de economie, crisis in relatie- en gezinsvorming? The Hague: CBS Bevolkingstrends.

de Graaf, N. D., de Graaf, P. M., Kraaykamp, G., \& Ultee, W. C. (2000). Familie-enquête Nederlandse Bevolking 2000. Department of Sociology, Radboud University Nijmegen. Den Haag: Data Archiving and Networked Services (DANS).

de Lange, M., Gesthuizen, M., \& Wolbers, M. H. J. (2012). Trends in labour market flexibilization among Dutch school-leavers: The impact of economic globalization on educational differences. International Sociology, 27(4), 529-550.

Deboosere, P., Lesthaeghe, R., Surkyn, J., Boulanger, P.-M., \& Lambert, A. (1997). Algemene Volks-en Woningtelling op 1 maart 1991. Huishoudens en gezinnen. Brussel: Nationaal Instituut voor de Statistiek.

Dreher, A. (2006). Does globalization affect growth? Evidence from a new index of globalization. Applied Economics, 38(10), 1091-1110.

Fokkema, T., de Valk, H., de Beer, J., \& van Duin, K. (2008). The Netherlands: Childbearing within the context of a 'Poldermodel' society. Demographic Research, 19, 743-794. 
Gebel, M., \& Giesecke, J. (2009). Fertilität-Ökonomische Unsicherheit und Fertilität. Die Wirkung von Beschäftigungsunsicherheit und Arbeitslosigkeit auf die Familiengründung in Ost- und Westdeutschland. Zeitschrift für Soziologie, 38(5), 399-419.

Hannum, E., \& Buchmann, C. (2003). The consequences of global educational expansion. Social science perspectives. Cambridge, MA: American Academy of Arts and Sciences.

Hoem, B. (2000). Entry into motherhood in Sweden: The influence of economic factors on the rise and fall in fertility, 1986-1997. Demographic Research, 2, 1-28.

Hofmann, B., \& Hohmeyer, K. (2013). Perceived economic uncertainty and fertility: Evidence from a labor market reform. Journal of Marriage and Family, 75, 503-521.

Inglehart, R. F. (1977). The silent revolution: Changing values and political styles among western publics. Princeton: Princeton University Press.

Inglehart, R. F. (1997). Modernization and postmodernization. Cultural, economic, and political change in 43 societies. Princeton: Princeton University Press.

Kalmijn, M. (1991). Shifting boundaries: Trends in religious and educational homogamy. American Sociological Review, 56, 786-800.

Klijzing, E. (2005). Globalization and the early life course. A description of selected and demographic trends. In H.-P. Blossfeld, E. Klijzing, M. Mills, \& K. Kurz (Eds.), Globalization, uncertainty and youth in society (pp. 25-49). London: Routledge.

Kravdal, Ø. (2002). The impact of individual and aggregate unemployment on fertility in Norway. Demographic Research, 6, 263-294.

Kreyenfeld, M. (2010). Uncertainties in female employment careers and the postponement of parenthood in Germany. European Sociological Review, 26(3), 351-366.

Kreyenfeld, M., Andersson, G., \& Pailhé, A. (2012). Economic uncertainty and family dynamics in Europe. Demographic Research, 27, 835-852.

Lesthaeghe, R., \& van de Kaa, D. J. (1986). Twee Demografische Transities? (Two demographic transitions?). In D. J. van de Kaa \& R. Lesthaeghe (Eds.), Bevolking: Groei en Krimp (Population: Growth and decline) (pp. 9-24). Deventer: Van Loghum Slaterus.

Liefbroer, A. C., \& Corijn, M. (1999). Who, what, where, and when? Specifying the impact of educational attainment and labour force participation on family formation. European Journal of Population, 15, 45-76.

Liefbroer, A. C., \& Merz, E.-M. (2009). Reproductive decision-making in a macro-micro perspective: Report on analysis of ESS data on cross-national differences in perceived norms concerning fertility-related behaviour to the European Commission within the 7th Framework Programme. Den Haag: Nederlands Interdisciplinair Demografisch Instituut (NIDI).

Liefbroer, A. C., \& Puy, J. (2005). De transitie naar volwassenheid en de rol van het overheidsbeleid. Een vergelijking van institutionele arrangementen in Nederland, Zweden, Groot-Brittannië en Spanje. Den Haag: NIDI.

McDonald, P. (1996). Demographic life transitions: An alternative theoretical paradigm. Health Transition Review, 6(Suppl), 385-392.

McDonald, P. (2002). Sustaining fertility through public policy: The range of options. Population, 57(3), 417-446.

Mills, M., \& Blossfeld, H.-P. (2005). Globalization, uncertainty and the early life course. A theoretical framework. In H.-P. Blossfeld, E. Klijzing, M. Mills, \& K. Kurz (Eds.), Globalization, uncertainty and youth in society (pp. 1-24). London: Routledge.

Neels. K. (2010). Temporal variation in unemployment rates and their association with tempo and quantum of fertility: Some evidence for Belgium, France and The Netherlands. Paper presented at the annual meeting of the Population Association of America, Dallas, April 17.

Neels, K., Theunynck, Z., \& Wood, J. (2012). Economic recession and first births in Europe: Recessioninduced postponement and recuperation of fertility in 14 European countries between 1970 and 2005. International Journal of Public Health, doi:10.1007/s00038-012-0390-9.

Oppenheimer, V. K. (1988). A theory of marriage timing. American Journal of Sociology, 94, 563-591.

Oppenheimer, V. K. (1994). Women's rising employment and the future of the family in industrial societies. Population and Development Review, 20, 293-342.

Oppenheimer, V. K., Kalmijn, M., \& Lim, N. (1997). Men's career development and marriage timing during a period of rising inequality. Demography, 34(3), 311-330.

Ranjan, P. (1999). Fertility behaviour under income uncertainty. European Journal of Population, 15(1), $25-43$. 
Rindfuss, R., \& VandenHeuvel, A. (1990). Cohabitation: A precursor to marriage or an alternative to being single? Population and Development Review, 16(4), 703-726.

Schmitt, C. (2008). Gender-specific effects of unemployment on family formation: A cross-national perspective. DIW Berlin, Discussion Papers 841.

Sobotka, T., Skirbekk, V., \& Philipov, D. (2009). De crisis en de vruchtbaarheid in de westerse wereld. Demos, 25(9), 2-4.

Sobotka, T., Skirbekk, V., \& Philipov, D. (2011). Economic recession and fertility in the developed world. Population and Development Review, 37(2), 267-307.

te Grotenhuis, M., Eisinga, R., van der Meer, T., \& Pelzer, B. (2012). Tanend appèl. De bijdrage van ontkerkelijking en ontzuiling aan het aantal CDA-zetels in de Tweede Kamer, 1970-2010. Religie \& Samenleving, 7(1), 70-92.

UIS. (2012). Data centre. Montreal: UNESCO Institute for Statistics. Retrieved May 29, 2012, from http://stats.uis.unesco.org/.

van de Kaa, D. J. (2002). The idea of a second demographic transition in industrialized countries. Paper presented at the sixth welfare policy seminar of the national institute of population and social security, Tokyo. Retrieved January 29, 2002, from http://www.ipss.go.jp/webj-ad/WebJournal.files/ population/2003_4/Kaa.pdf.

Visser, J. (2002). The first part-time economy in the world: A model to be followed? Journal of European Social Policy, 12, 23-42. 